\title{
Experimental Study of Boilover in Crude Oil Fires
}

\author{
HIROSHI KOSEKI
}

Fire Research Institute

14-1, 3-Chome Nakahara Mitaka, Tokyo 181, Japan

\section{MATTI KOKKALA}

VTT, Fire Technology Laboratory

SF-02150 Espoo, Finland

\section{GEORGE W. MULHOLLAND}

Building and Fire Research Laboratory

National Institute of Standards and Technology

Gaithersburg, Maryland 20899, USA

\section{ABSTRACT}

An experimental study of boilover phenomena in connection with crude oil and kerosene pool fires was carried out in the large scale test facilities of the Fire Research Institute of Japan. Arabian light crude oil was burned in steel pans ranging from a circular one with a diameter of $0.3 \mathrm{~m}$ to a square one with a $2.7 \mathrm{~m}$ side. An oil layer of $10 \mathrm{~mm}$ to $100 \mathrm{~mm}$ was floating on water in the pans.

The intensity of boilover was found to increase with increasing fuel thickness. An almost tenfold increase in the amount of unburned residue was found to occur as the layer thickness was increased from $40 \mathrm{~mm}$ to $50 \mathrm{~mm}$. Results of measurements of liquid and gas temperatures, burning rates and radiative heat outputs are reported.

Key words: crude oil, kerosene, boilover, hot zones, thermal radiation, burning rate

\section{INTRODUCTION}

Because of their abundance the fire safety of various crude oil storage facilities must be of great concern. Although much is known about boilover in connection with oil tank fires, serious accidents still occur ${ }^{1.2 .3}$. Recently, the environmental aspects of crude oil burning have gained more attention. Controlled burning has been considered as a possible means of limiting the spread of oil after leakage from an oil tanker.

The conditions under which boilover occurs have been studied, e.g., by Hall $1^{4}$, by Burgoyne and $\mathrm{Katan}^{53}$, by Blinov and Khudyakov's), and more recently by Hasegawa ${ }^{73}$. It has been shown, that a necessary condition for boilover is that an isothermal layer or a so called hot zone be formed in the burning liquid. The thickness of the hot zone increases with time; in a big 
tank it may grow to a thickness of several meters. When the lower boundary of the hot zone reaches a layer of water on the bottom of the tank a sudden vaporization of water may occur. In spite of the rather extensive studies, complete understanding of the mechanisms of boilover is still lacking.

Boiling of water may also occur under a thin layer of fuel and without the existence of the hot zone. The necessary condition is that the burning temperature of the liquid be so high that the water is heated to its boiling point as a result of conduction, convection and radiation through the fuel. In this case, the boiling increases the burning rate by only a factor of about two. To contrast this behavior with boilover, this phenomenon is referred to a thin layer boilover. The burning of thin layers of crude oil have been studied by Twardus and Brzustowski ${ }^{\mathrm{e})}$, by Evans et al. ${ }^{9 x}$, by lto et al. ${ }^{10 x}$, by Petty ${ }^{112}$ and us $^{122}$.

In this work, we have studied the effect of the thickness of the crude oil layer on boilover. Another important aspect of this study is the measurement. of the amount of residue in pan. This information is needed to evaluate the potential effectiveness of burning as a method of cleaning up crude oil spills. To improve our understanding of the boilover phenomenon, kerosene, which is also a mixture of hydrocarbons with a narrower and lower range of boiling points than crude oil, was burned under similar conditions.

\section{EXPERIMENTAL,}

A schematic of the experimental setup is shown in Figure 1. Steel pans were placed at the center of the floor of the main test room of the large scale test building of the Fire Research Institute of Japan. For safety reasons the test pan was placed inside a large vessel to restrict the spread of oil when boilover occurred. The test room is $24 \mathrm{~m} \times 24 \mathrm{~m}$ and $20 \mathrm{~m}$ high, i.e., big enough so that the walls and the ceiling do not influence the fire. Arabian light crude oil and kerosene were used as fuels. Properties of the Arabian light crude oil are given in Table 1.

The tests were made using circular pans of dianeter, $0.3 \mathrm{~m}, 0.6 \mathrm{~m}, 1 \mathrm{~m}$ and 2 $\mathrm{m}$, and a square pan with $2.7 \mathrm{~m}$ sides. We define the effective diameter of the square pan as the diameter of a circle $(3.05 \mathrm{~m})$ with area equal to the square pan. The pans were filled with water and fuel so that only a $20 \mathrm{~mm}$ lip was left for the pans except the largest, which had a $30 \mathrm{~mm}$ lip. The fuel layer thickness was varied over the range $10 \mathrm{~mm} \sim 100 \mathrm{~mm}$. The measurements consisted of fuel level regression rate, external radiation, temperatures inside

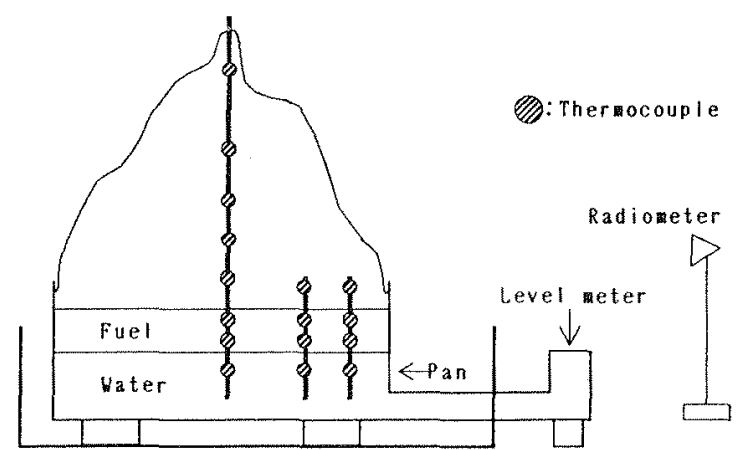

Table J. Properties of the Arabian light crude oil

\begin{tabular}{lc} 
Density & $850 \mathrm{~kg} / \mathrm{m}^{3}$ \\
& $\left(\right.$ at $\left.5^{\circ} \mathrm{C}\right)$ \\
Flash point & $-15^{\circ} \mathrm{C}$ \\
Kinematic viscosity & $6.9 \times 10^{-7} \mathrm{~m}^{2} / \mathrm{s}$ \\
& $\left(\right.$ at $\left.30^{\circ} \mathrm{C}\right)$ \\
Pour temperature & $-15^{\circ} \mathrm{C}$ \\
Carbon fraction & 0.838 \\
\hline
\end{tabular}

$\leftarrow$ Figure 1 Schematic diagram of the apparatus 
the liquid and in the flame. After fire extinction, the amount of residual fuel left in the pan was also measured.

The fuel regression rate was measured with a float-type level meter connected to the pan. Until boiling occurs the regression rate is almost equal to the burning rate. Although the lip height varied during the test, the effect of the variations on the burning rate is believed to be small because of the thin initial layer of the fuel.

Radiation from the entire flame to the surroundings was measured by three thermopile-type wide angle radiometers. They were pointing horizontally at the level of the pan edge towards the flame axis at radial distances of $L / D=$ $3,5,7$, where $L$ is the distance from the axis to the radiometer and $D$ is the pan diameter.

The temperatures inside the flame and in the fuel and water were measured using $0.3 \mathrm{~mm}$ diameter $\mathrm{K}$-type thermocouples sheathed with a $1.6 \mathrm{~mm}$ diameter stainless steel tube. Thermocouples were located at various heights along the pan axis, and at radial distances of $0.17 \mathrm{~m}$ and $0.39 \mathrm{~m}$ from the axis. The outputs of the sensors were recorded continuously on a strip chart recorder or on a digital data acquisition system with a scanning period in the range of $10 \mathrm{~s}$ to $60 \mathrm{~s}$. After boilover and extinction, unburned fuel was collected with a beaker and was easily separated from the water. The mass of the cooled residue was measured with a balance.

In some of the tests smoke emission and combustion efficiency were measured, but these results are reported elsewhere ${ }^{12}$.

\section{RESULTS AND DISCUSSION}

A summary of the key test results is given in Table 2 . In cases where the test was repeated under the same conditions the result shown is the average of the tests. Fuel regression rate and radiation data are consistent with previous results ${ }^{12}$.

Time history of fuel regression rate

Figure 2 shows the time history of the fuel regression rate(burning rate) of $30 \mathrm{~mm}$ crude oil layer in a $1 \mathrm{~m}$ diameter pan. About two minutes after ignition, fuel regression rate reaches a plateau and is maintained until thin lay-

Table 2 Summary of test results

\begin{tabular}{|c|c|c|c|c|c|}
\hline $\begin{array}{l}\text { Pan } \\
\text { diameter } \\
\text { (m) }\end{array}$ & $\begin{array}{l}\text { Fuel } \\
\text { thickness } \\
\quad \text { (mm) }\end{array}$ & $\begin{array}{l}\text { Average fuel } \\
\text { regression rate } \\
\text { (mm/min) }\end{array}$ & $\begin{array}{l}\text { Maximum fuel } \\
\text { regression rate } \\
(\mathrm{mm} / \mathrm{min})\end{array}$ & $\begin{array}{l}\text { Time to } \\
\text { boilover } \\
\text { (min) }\end{array}$ & $\begin{array}{l}\text { Heat wave } \\
\text { regression } \\
\text { rate(mm/min) }\end{array}$ \\
\hline 0.3 & 35 & - & - & 10.2 & 3.4 \\
\hline \multirow{2}{*}{0.6} & 20 & 1.4 & 2.8 & $8.1 \sim 8.3$ & 2.5 \\
\hline & 69 & 2.0 & 21.5 & 15.7 & 2.4 \\
\hline \multirow{4}{*}{1} & 20 & $1.5 \sim 1.8$ & 5.9 & $7.1 \sim 8.5$ & 2.8 \\
\hline & 40 & 2.2 & 5.6 & 16.3 & 2.5 \\
\hline & 60 & 2.4 & 8.1 & 21.8 & 2.8 \\
\hline & 100 & 2.2 & $>20$ & 32.1 & 3.1 \\
\hline 2 & 20 & $1.7 \sim 2.0$ & 3.4 & $6.2 \sim 7.5$ & 3.2 \\
\hline $2.7 \mathrm{sa}$ & 27 & 2.3 & 2.6 & 6.7 & 4.1 \\
\hline
\end{tabular}




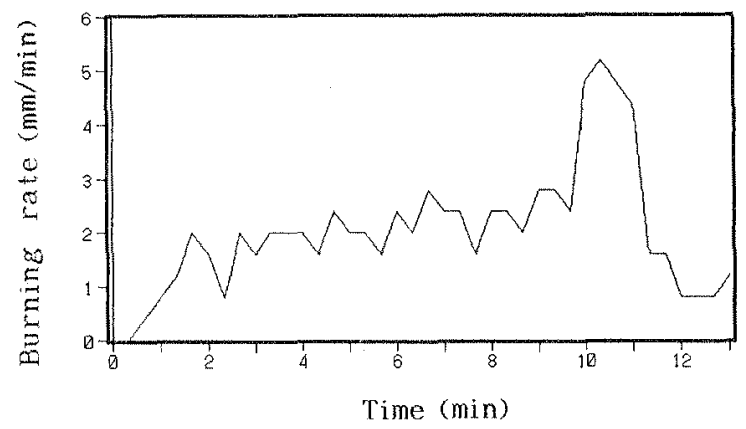

Figure 2 Time history of fuel regression rate (1 $\mathrm{m}$ pan, $30 \mathrm{~mm}$ initial fuel layer thickness of crude oil)

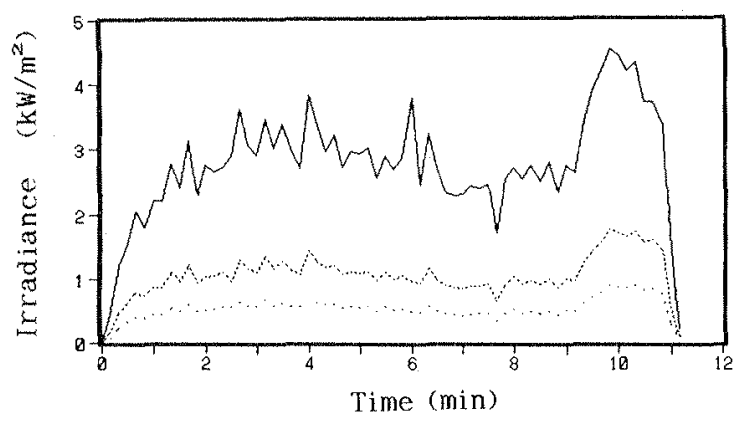

(a) crude oil (initial fuel layer thickness $30 \mathrm{~mm}$ ) - $L / D=3 \quad \cdots \cdot L / D=5$ $\cdots L / D=7$

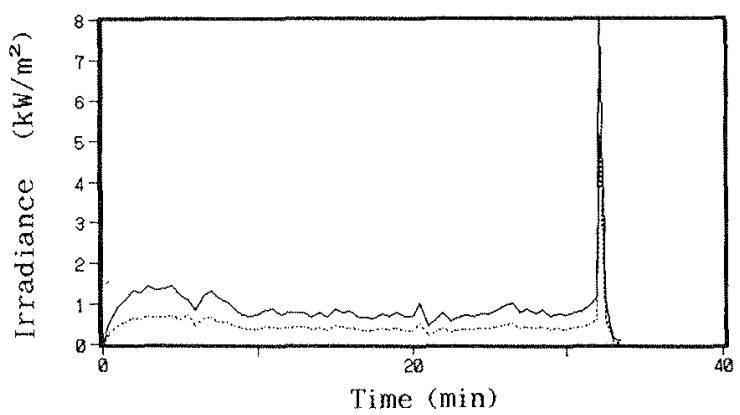

(b) crude oil (initial fuel layer thickness $100 \mathrm{~mm}$ ) $-L / D=5 \quad \cdots \cdot L / D=7$

(c) kerosene (initial fuel layer thickness $100 \mathrm{~mm}$ ) $-L D=5$

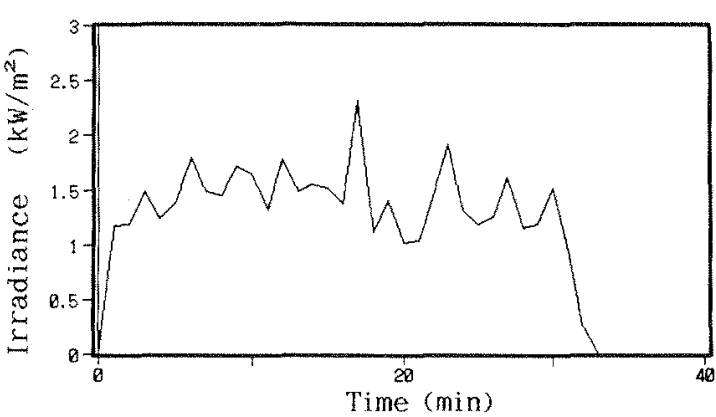

Figure 3 Time history of radiation from $1 \mathrm{~m}$ pan fire, l: distance between pan center and radiometer, $D$ : pan diameter 
er boilover occurred. At the end of burning, water splashing occurred and fuel regression rate increased due to thin layer boilover.

Time history of radiation

Figure 3 shows the time history of the radiative heat flux at various distances in three different tests in a $1 \mathrm{~m}$ diameter pan. Figures $3(\mathbf{a})$ and $3(\mathbf{b})$ are from tests with a crude oil of layers $30 \mathrm{~mm}$ and $100 \mathrm{~mm}$, respectively. Figure 3(c) is from a test with $100 \mathrm{~mm}$ layer of kerosene. Figure 3(b) represents a test with a boilover at the end of burning, whereas in the other two tests only a thin layer boilover, water and fuel splashing occurred at the end of the burning. The splashing of water and fuel at the end of kerosene burnings did not result in a measurable increase in the radiative heat flux.

Time history of fuel temperature

The thermocouples at the same height at different radial distances from the axis in the fuel layer showed that the radial temperature variations were not significant. The results confirm those of Hasegawa, who found for a mixture of diesel oil and gasoline a temperature variation of $\pm 4^{\circ} \mathrm{C}$ at the same level.

Figure 4 shows the temperatures as a function of time at various positions originally inside the liquid in two tests with $100 \mathrm{~mm}$ layers of crude oil

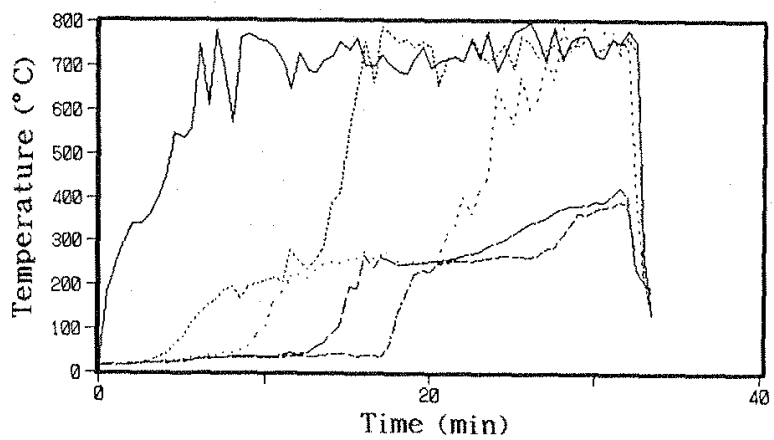

(a) crude oil (initial fuel layer thickness $100 \mathrm{~mm}$ )

$$
\begin{aligned}
& \begin{array}{lll}
-12 & \cdots \cdot 32 & \cdots \\
-72
\end{array} \\
& \begin{array}{lll}
-72 & -.-92
\end{array}
\end{aligned}
$$

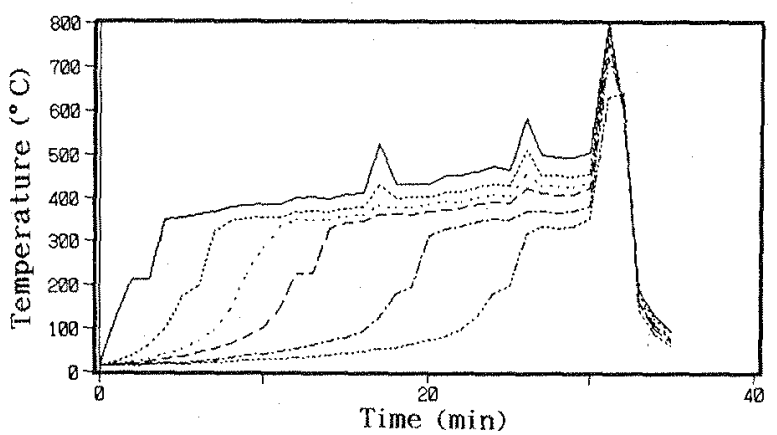

(b) kerosene (initial fuel layer thickness $100 \mathrm{~mm}$ )

$$
-6 \quad \cdots \cdot 16 \quad \cdots 26
$$$$
--36 \quad-\cdots 56 \quad \cdots-76
$$

Figure 4 Time history of liquid temperature in $1 \mathrm{~m}$ pan fire. Numbers mean the vertical distances between thermocouples and initial fuel surface (unit: mm). Fuel level was not controlled after ignition. 
(Figure $4(\mathrm{a})$ ) and kerosene(Figure $4(\mathrm{~b})$ ). A rapid increase of temperature can be seen after the surface level has regressed exposing a thermocouple. No correction for possible soot deposition on the thermocouple or radiation effects associated with the thermocouple were made for the temperature measurements given in Figures 4 and 5.

In the crude oil fire, the surface temperature rises first to about $220^{\circ} \mathrm{C}$. After several minutes, a hot zone begins to form as indicated by two or more thermocouples having the same temperature. The temperature of the hot zone increases slowly. For example, $20 \mathrm{~min}$ after ignition, the three lowest thermocouples all indicate a temperature of about $265^{\circ} \mathrm{C}$ suggesting that the thickness of the hot zone is more than $40 \mathrm{~mm}$. The temperature of the layer increases to about $400^{\circ} \mathrm{C}$ before boilover occurs.

In the kerosene fire, the surface temperature rises first to about $210^{\circ} \mathrm{C}$ but decreases slightly towards the end of the burning. No isothermal layer is formed; the temperatures measured by the thermocouples remain approximately constant only as long as part of the thermocouple is touching the surface. Because of surface tension, the thermocouples may be in contact with the surface longer than expected from the surface regression rate only.

Figure 5 shows the temperature distribution close to the fuel surface (both above and below) at various moments in the tests of Figure 4 in $100 \mathrm{~mm}$ layers of crude oil fire (Figure 5(a)) and kerosene fire (Figure 5(b)). In Figure 5(a), the positions of the surface and the lower boundary of the hot zone, which were calculated from data of surface regression rate and heat wave regression rate, are shown by dashed lines. Both the hot zone thickness and the temperature of the hot zone increase toward the end of the burning. A hot zone was not observed until about 10 minutes after ignition. There is a small gradient of temperature inside the hot zone with the surface $10 \sim 20{ }^{\circ} \mathrm{C}$ warmer than the bottom of the zone. The surface temperature increased with time, which is different from Petty* $\mathrm{s}$ crude oil fire result for a $50 \mathrm{~mm}$ layer fuel in $2 \mathrm{~m} \mathrm{pan}^{11}$. He reported that the surface temperature did not change until the end of burning.

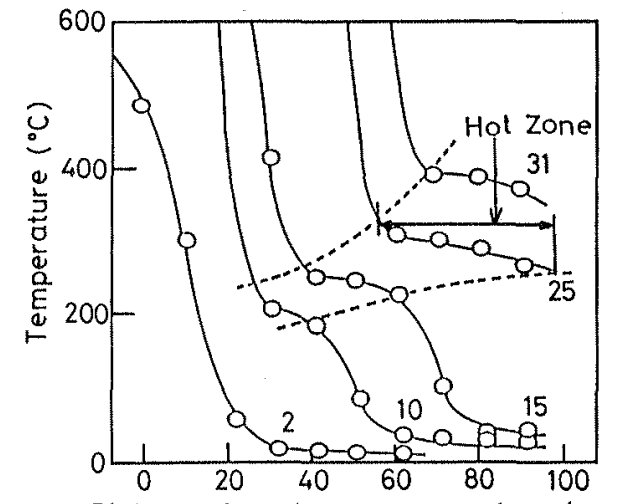

Distance from initial fuel surface $(\mathrm{mm})$ (a) crude oil

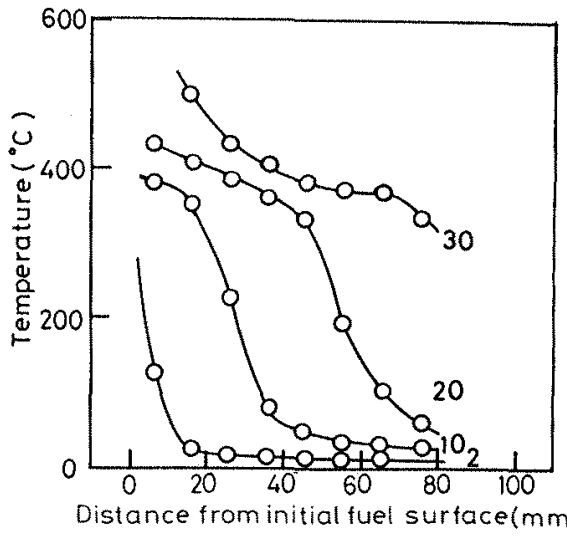

(b) kerosene

Figure 5 Development of vertical temperature profile with $100 \mathrm{~mm}$ initial fuel thickness in $1 \mathrm{~m}$ pan fires which were from the same tests of Figure 4 . Numbers in the figures are times after ignition(unit: min). Dash lines show range of hot zone. 
In the case of the kerosene fire, Figure $5(\mathrm{~b})$, the fuel temperature decreased steeply with vertical distance from fuel surface, with a gradient of about $15^{\circ} \mathrm{C} / \mathrm{mm}$ compared to a gradient of about $1^{\circ} \mathrm{C} / \mathrm{mm}$ for the case of crude oil. Clearly, there is no isothermal layer for burning kerosene.

In the crude oil fire, the thermocouples embedded in the water sublayer indicated temperatures of higher than $100^{\circ} \mathrm{C}$ before boilover occurred. Blinov and Khudyakov ${ }^{63}$ reported boiling temperatures of water of about $130^{\circ} \mathrm{C}$, but we think their result is doubtful. The high temperature may be partly due to superheating of the water, which also explains the enormous intensity of the boilover. In our case, however, the interface between water and oil was not calm, and therefore the thermocouple close to the interface may show an average of the water and oil temperatures. Also, the thermocouple itself is expected to be a nucleation site for boiling, and such boiling is not expected to be accompanied by significant superheating.

Time to the start of boilover

Figure 6 shows the relationship between the initial fuel thickness, Ho, and the time to the commencement of boilover in various pans with crude oil on a water sublayer. There is large scatter among the tests, but a linear fit to the data gives a slope of $u=3.1 \mathrm{~mm} / \mathrm{min}$. Here $u$ is equal to the average hot zone regression rate (or heat wave regression rate).

As seen from Table 2 the average surface regression rate is about 2.2 $\mathrm{mm} / \mathrm{min}$, and therefore the thickness of the hot zone increases with an average rate of $0.9 \mathrm{~mm} / \mathrm{min}$. In some tests the thickness of the hot zone increased much more rapidly. For example in the test shown in Figure $4(a)$ the rate of increase of the thickness was about $2 \mathrm{~mm} / \mathrm{min}$. The causes of the large variations are not known.

We have assumed that the thickness of the hot zone increased lineally with

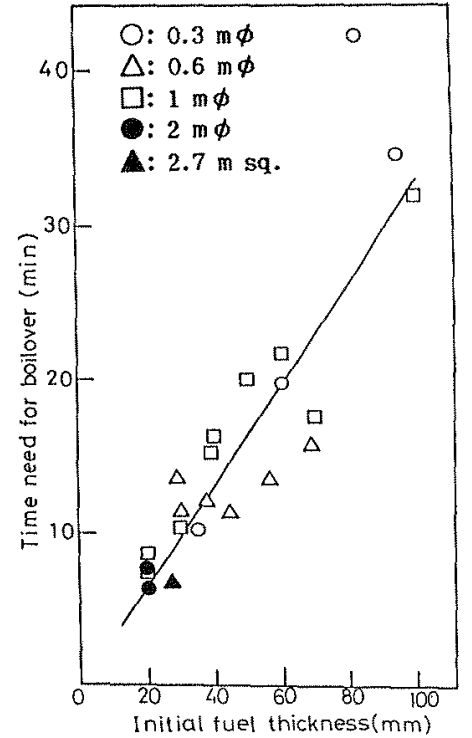

Figure 6 Relationship between time to boilover and initial fuel thickness

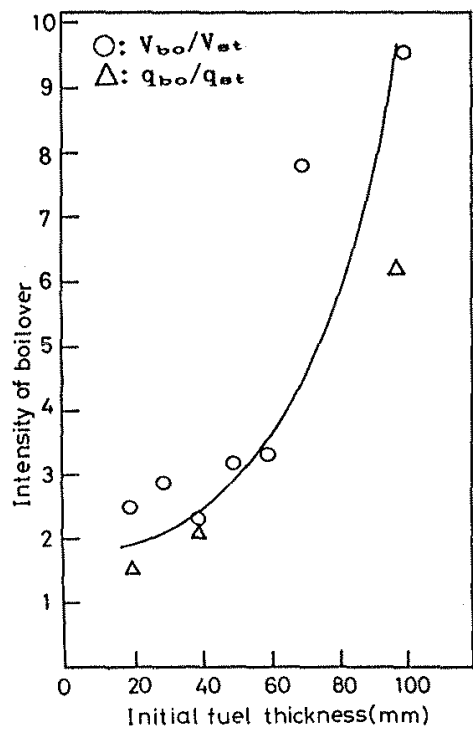

Figure 7 Relationship between intensity of boilover and initial fuel thickness in $1 \mathrm{~m}$ crude oil pan fire. 
time. Blinov and Khudyakov ${ }^{6}$ have reported that the thickness approaches a constant value at long time according to the equation;

$H_{h z}=H_{n z, \max } \times[1-\exp (t / j)]$,

where $t$ is time and $j$ is a time constant characteristic of each fuel and pan. $\mathrm{H}_{\mathrm{hz}}$ is the hot zone thickness and $\mathrm{H}_{\mathrm{hz} \text {, max }}$ is the maximum hot zone thickness during the burning. However their results and this equation show that during the early stage of burning $\mathrm{H}_{\mathrm{n} \text {. }}$ is approximately a linear function of time. The expression of Blinov and Khudyakov is not, however, consistent with the data of Idemitsu ${ }^{14}$, which shows a linear increase of the thickness of the hot zone until $90 \mathrm{~min}$, when the boilover occurred in a $1.8 \mathrm{~m}$ crude oil pan. There is a need for additional experiments to resolve this discrepancy.

\section{Intensity of boilover}

We characterize the intensity of boilover using the ratio

$\Psi=\mathrm{v}_{\mathrm{bo}} / \mathrm{v}_{\mathrm{at}}$

where $v_{s t}$ is the average fuel regression rate during the quasi-steady state and $v_{b o}$ is the maximum fuel regression rate during the boilover. Another measure of the intensify of boilover is the ratio of irradiance, $q_{b o} / q_{a t}$, where $q_{b o}$ is the maximum irradiance at $L / D=5$ during boilover and $q_{s t}$ is the average irradiance at $L / D=5$ during quasi-steady burning.

In spite of limited and large scatter of data, Figure 7 shows that the intensity of boilover increased wh increasing initial fuel layer thickness in the $1 \mathrm{~m}$ diameter pan. The deeper the initial fuel layer thickness was, the longer burning continued before boilover. For this reason, the intensity of boilover, $\Psi$, increased as the hot zone became thicker and its temperature became higher. Figure 7 shows that there is a transition to high intensity boilover for initial fuel level thickness greater than $60 \mathrm{~mm}$.

Influence of the pan diameter

The surface regression rate was almost constant for diameters greater than $1 \mathrm{~m}$. In pans smaller than $1 \mathrm{~m}$ the regression rate was slightly lower and was consistent with Babrauskas' $s^{15}$ equation for quasi-steady state burning.

$\mathrm{v}=\mathrm{v}_{\infty} \times(1-\exp (-\kappa \times \mathrm{D}))$

where $v_{\infty}$ is the burning rate for an infinite diameter pan and the coefficient $\kappa$ is reported ${ }^{15}$ ) as $2.8 \mathrm{~m}^{-1}$ for crude oil.

According to Blinov and Khudyakov ${ }^{6)}$ the hot zone regression rate of crude oil in a $2.6 \mathrm{~m}$ pan is twice as high as observed in a $1.3 \mathrm{~m}$ pan. In a smaller pan neither a hot zone nor boilover was observed. Hasegawa found both a minimum and a maximum diameter within which the hot zone was formed in a mixture of diesel oil and gasoline. He did not find any hot zone in pans with a diameter larger than $0.9 \mathrm{~m}$.

In our tests the hot zone regression rate was not significantly affected by the pan diameter over the range $0.3 \mathrm{~m}$ in diameter to $2.7 \mathrm{~m}$ side of square. For all of the tests the average hot zone regression rates were within 2.5 and 4.4 $\mathrm{mm} / \mathrm{min}$. Both the maximum and the minimum values were obtained in the tests with the $0.6 \mathrm{~m}$ diameter pool.

The influence of the pan diameter on the intensity of boilover was studied in a series of tests with a $20 \mathrm{~mm}$ fuel layer. The results, shown in Figure 8, 
indicate a decrease of the relative intensity of boilover with increasing pan diameter. Part of the decrease was due to the increase of the steady state surface regression rate, $v$. The difference between $u$, the heat wave regression rate, and $v$ govern the hot zone thickness and the intensity of the boilover. In the largest pan fire, boilover did not seem to occur. We estimate that the hot zone must be at least $5 \sim 10 \mathrm{~mm}$ for intense boilover to occur.

\section{Unburned residue}

Immediately after flame extinction the fuel formed a froth filling the pan. After the fuel had cooled the thickness of the residue was measured. With thin layers the residue was collected from the surface and the effective thickness was measured based on the weight. Table 3 shows the thickness of the residue after boilover in the tests in a $1 \mathrm{~m}$ pan with different initial fuel layer thicknesses.

From Table 3 we can see that when the initial fuel layer is $40 \mathrm{~mm}$ or less the thickness of the residue is of the order of $1 \mathrm{~mm}$. For layer thicknesses of $50 \mathrm{~mm}$ or more the thickness of the residue is of the order of $10 \mathrm{~mm}$; that is, about $10 \sim 20 \%$ of the initial fuel was unburned. This result is similar with Petty result ${ }^{x}$, that $5 \sim 15 \%$ of initial fuel was unburned for a $50 \mathrm{~mm}$ fuel layer in a $2 \mathrm{~m}$ pan. This sudden change in residue fraction at the $50 \mathrm{~mm}$ fuel layer is probably a result of the formation of a hot zone. The large amount of unburned fuel for a layer thicknesses greater than $50 \mathrm{~mm}$ is thought to result from the vigorous mixing of the hot zone and water at boilover. For smaller fuel layers, apparently no hot zone was formed.

The properties of the residue were very different from the original fuel. For example, the flash point was higher than $80^{\circ} \mathrm{C}$ and the density was about $950 \sim 990 \mathrm{~kg} / \mathrm{m}^{3}$ compared to $850 \mathrm{~kg} / \mathrm{m}^{3}$ for the fresh crude oil. When the residue was kept in a separate vessel it became solid-like in about one day. If the residue was reignited after it had cooled down below the flash point, it burned for several minutes, but because of the boiling of the water sublayer it could never be completely consumed by burning. The water lost from the sublayer was a few centimeters at most, which suggests that the depth of the water does not have a large effect on the amount of residue.

\section{SUMMARY AND CONCLUSIONS}

Burning rates, hot zone regression rates and external radiation values 
were measured for Arabian light crude oil burning in pans ranging from a circular one with a diameter of $0.3 \mathrm{~m}$ to a square one with $2.7 \mathrm{~m}$ sides.

The hot zone regression rate was found to have a value of about $3 \mathrm{~mm} / \mathrm{min}$ independent of pan diameter over the range $0.3 \mathrm{~m}$ to $1 \mathrm{~m}$. With a constant fuel thickness the relative increase of the burning rate during boilover decreased with increasing pan diameter.

When boilover occurred, the burning rate and the external radiation increased dramatically. For initial fuel layers greater than about $50 \mathrm{~mm}$, there were greatly increased burning rates during boilover with a 10 fold increase residue for a $100 \mathrm{~mm}$ layer and also a 7 fold increase in the unburned fuel. The maximum intensity of burning was found to be related to the hot zone thickness and to the initial fuel thickness. A hot zone of at least $5 \sim 10 \mathrm{~mm}$ layer thickness was found to be necessary for boilover.

\section{REFERENCE}

1. Henry,M+ and Klem, T., "Scores Die in Tank Fire Boilover", Fire Service Today p.11 June 1983

2. "Safety Codes in Doubt after Britain's Largest Postwar Refinery Fire", Fire Prevention, 169, 36-38, 1983.

3. "Tank Farm Burns for a Whole Week", Fire Prevention Bulletin, 082, $19-26,1988$.

4. Hall,H.H.,"Oil-Tank-Fire Boilover", Mechanical Engineering 47(7) p.540, 1925

5. Burgoyne, J.H. and Katan, L.L.,"Fire $\mathbf{s}$ in Open Tanks of Petroleum Products: Some Fundamental Aspects", J. of the Institute of Petroleum, 33 p. 158,1947

6. Blinov, V.I. and Khudyakov,G.N.,"Diffusion Burning of Liquids", T-1490 ASTIA AD 296762, p.118, 1961

7. Hasegawa,K.,"Experimental Study on the Mechanism of Hot Zone Formation in Open-Tank Fires", Fire Safety Science, Proceedings of the Second International Symposium, p.221, 1989

8. Twardus, E.M. and Brzustowski, T.A.,"The Burning of Crude Oil Spilled on Water", Archivum Combustionis, 1 p.49, 1981

9. Evans, D., Baum,H., McCaffrey,B., Mulholland, G., and Harkleroad,M., Manders, W., "Combustion of Oil on Water" NBSIR 86-3420, 1987

10. Ito,A., Inamura, T., Saito, $\mathrm{K}$ and Evans, D.,"Holographic Interferometry Temperature Measurements in Liquids for Pool Fires", Proceedings of 3rd ASME-JSME Joint Thermal Engineering Conference, March 1991.

11. Petty, S.E., "Combustion of Crude Oil on Water", Fire Safety Journal, 5 p. 123,1983

12. Koseki,H., and Mulholland,G.,"The Effect of Diameter on the Burning of Crude Oil Pool Fires", Fire Technology, Vol.27(1) p.54, 1991

13. Society of Petroleum, "Petroleum Handbook", Asakura Syoten, Tokyo, 1982

14. Report of Idemitsu Kosan Co. Ltd.,"Crude Oil and its Combustion", 1985

15. Babrauskas, V.,"Free Burning Fires", Fire Safety Journal, 11 p.33 1986 